\title{
Epistaxis Management
}

\author{
Hesham A. Abdesallam, Ali K. Mahrous, \& Abdelsalam H. Hashim \\ Otolaryngology/ Head and Neck Surgery Department,
}

\begin{abstract}
:
Introduction: Epistaxis is common and has been reported to occur in up to 60 percent of the general population. The affected person usually does not seek medical attention, particularly if the bleeding is minor or self-limited. In rare cases, however, massive nasal bleeding can lead to death. The nose has an abundant blood supply. The arterial supply to the nose comes from carotid arteries. Nasal bleeding usually responds to first-aid measures. When epistaxis does not respond to simple measures, the source of the bleeding should be located and treated appropriately.

There is no unanimity amongst Otorhinolaryngologists in terms of the sequence of different treatment methods in Epistaxis patients. We aimed in this study to examine our existing practice in terms of management of epistaxis, and to try to come up with suggestions of sequential treatment steps.

This is a retrospective study conducted from November 2004 to January 2005 in the Otolaryngology Department in Midway Maritime Hospital.

Subjects and Methods: The study group consisted of 100 case notes requested. The demographic data of the patients were collected and the history of epistaxis in each patient.

Results: The study showed the peak of incidence of epistaxis (66\%) was in adults (51-91 years old). No sex predilection. It was mostly spontaneous. $60 \%$ of the patients presented for the first time. $63 \%$ of the patients have co-morbid conditions. $60 \%$ of the patients needed hospital admission. The patients were treated with different measures.

Conclusion: We concluded that the cases of epistaxis caused by trauma in our series is far less than expected. Co-morbidity plays a major role in the causation of epistaxis according to this study.

We recommend the use of chemical cautery, merocele or both as the first line of local treatment of epistaxis. If it does not work, Rapid Rhino with or without anterior packing should be considered. If this does not work, then sphenopalatine artery ligation is the next step.
\end{abstract}

\section{Introduction}

Epistaxis is defined as bleeding from the nostril, nasal cavity, or nasopharynx. It is a frequent Emergency Department (ED) complaint and often causes significant anxiety in patients and clinicians. (Choudhury et al, 2004).

Epistaxis is common, particularly if the bleeding is minor or self-limited. In rare cases, however, massive nasal bleeding can lead to death. (Tan and Calhoun,. 1999).

\section{Arterial supply of the nose, (Fig. 1)}

The nose, like the rest of the face, has an abundant blood supply. The arterial supply to the nose may be principally divided into (1) branches from the internal carotid, namely the branches of the anterior and posterior ethmoid arteries from the ophthalmic artery, and (2) branches from the external carotid, namely the sphenopalatine, greater palatine, superior labial, and angular artery.

Internally, the lateral nasal wall is supplied by the sphenopalatine artery posteroinferiorly and by the anterior and posterior ethmoid arteries superiorly. The nasal septum also derives its blood supply from the sphenopalatine and the anterior and posterior ethmoid arteries with the added contribution of the superior labial artery (anteriorly) and the greater palatine artery (posteriorly). The Kiesselbach 


\section{Epistaxis Management}

plexus, or the Little area, represents a region in the anteroinferior third of the nasal septum, where all 3 of the chief blood supplies to the internal nose converge. (Jafek., 1996)

Most cases of epistaxis occur in the anterior part of the nose, with the bleeding usually arising from the rich arterial anastomoses of the nasal septum (Kiesselbach's plexus). Posterior epistaxis generally arises from the posterior nasal cavity via branches of the sphenopalatine arteries. Such bleeding usually occurs behind the posterior portion of the middle turbinate or at the posterior superior roof of the nasal cavity. (Koh et al., 2000)

\section{Review of Literature \& Aetiology}

Epistaxis is a very common ENT emergency. Known aetiological factors include trauma, local inflammation, hypertension, clotting diatheses, blood vessel abnormalities and nasal tumours. Many drugs have been reported to cause epistaxis, including warfarin, dipyridamole, thioridazine, and even the oral contraceptive pill. In elderly epistaxis patients the non-steroidal anti-inflammatory drugs (NSAIDs) are also one of the causes. (Pond and Sizeland, 2000)

\section{Evaluation of Epistaxis}

Initial management should always begin with evaluation of the patient's blood pressure and heart rate. Fluid resuscitation may be necessary in the epistaxis patient. Once the patient is stable, a full history and physical examination can be pursued. (Srinivasan, 2000)

After that, anterior rhinoscopy is sometimes sufficient, but in most of the time a nasal endoscopic exam should be pursued. This will help dictate subsequent treatment. There are patients who are bleeding so profusely that any exam is difficult. These patients require more immediate interve-ntion. (Marks, 2000)

Nasal bleeding usually responds to first-aid measures such as compression. When epistaxis does not respond to simple measures, the source of the bleeding should be located and treated appropriately. (Frazee and Hauser, 2000)
So, we aimed in this study to examine our existing practice in Bab Al-Shaaria University Hospital in terms of management of epistaxis. And to try, if possible, to come up with suggestions, which may help the juniors, with clear guidance, by unifying the steps of treatment.

\section{Subjects and methods}

This was a retrospective study conducted from November 2004 to January 2005 in the Otolaryngology Department in Midway Maritime Hospital, Gillingham, Kent, UK. The study group consisted of 100 case notes requested, from which 81 identified, 73 used for analysis and 8 excluded due to poor note keeping. The demographic data of the patients were collected. In addition, the history of epistaxis in each patient such as: onset of bleeding, causes, associated co-morbidity, recurrence, hospital admission, and lines of treatment used.

\section{Results}

This study consisted of sample size of 73 notes of patients who attended the emergency department with epistaxis, then referred to our ENT department to be managed by a specialist. Among these notes, of which 52 patients presented once only, 14 patients had 2 attendances, 3 patients had 3 attendances, 1 patient had 4 attendances, 1 patient had 5 attendances and 2 patients had 6 attendances. So, the overall attendances to the ENT department from November 2004 to January 2005 were 110 attendances.

The patients were of different age groups, as there were $12(16 \%)$ children < 16 years old, 13 (18\%) were adults $17-50$ years old and 48 (66\%) were adults 51- 91 years old. While, the gender distribution of the cases was: $38(52 \%)$ females and 35 patients $(48 \%)$ males.

After control of the epistaxis and stabilization of the patients a full history was taken that shows the bleeding was spontaneous in 72 patients $(98 \%)$ and traumatic in 1 patient. Also, $44(60 \%)$ 


\section{Hesham A. Abdesallam et al}

presented for 1st time, 28 (38\%) patients with recurrent episode and in 1 patient, it cannot be determined.

From the history, there were other associated diseases that may have contributed to the bleeding. 13 patients had hypertension, 19 patients had hypertension with other miscellaneous conditions and there were 5 patients on a regular anticoagulant (Warfarin), while 27 patients $(37 \%)$ had no co-morbid conditions.

The hospital admission among 110 attendances was: 66 attendances (60\%). These were admitted for further assessment by the nasal endoscope, by senior staff, and thorough follow up. 21 of them (19\%) discharged at the same day and in $23(21 \%)$ there was no clear data about their admission policy. The rest of the 44 attendances were managed as outpatient cases.

The treatment lines used for control of the bleeding in patients were: 13 of them required chemical cautery alone, 12 required Merocel packing alone, 10 required a combination of both and the rest managed under general anaesthesia in the operating theatre by combination of Rapid Rhino (RR), Brighton Balloon (BB), Bisthmus Iodoform paraffin Paste (BIPP), Merocel and $\backslash$ or cautery.

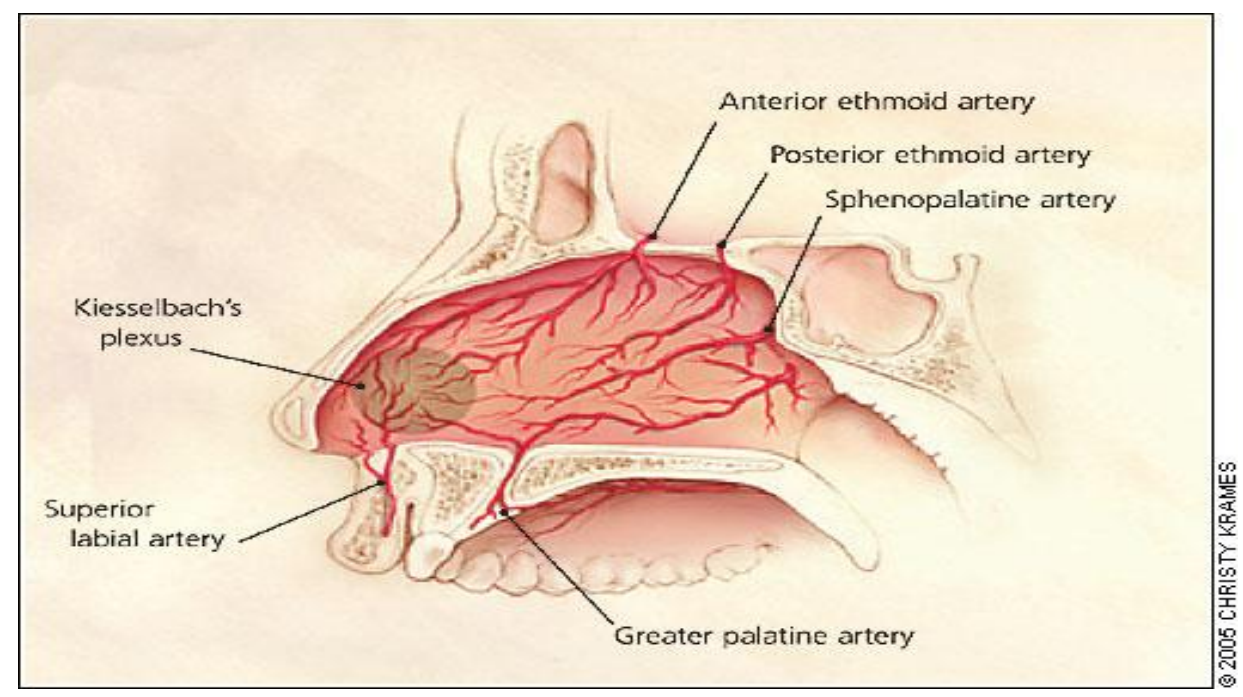

Figure 1. Vascular anatomy of nasal septal blood supply. (Koh E, et al, 2000)

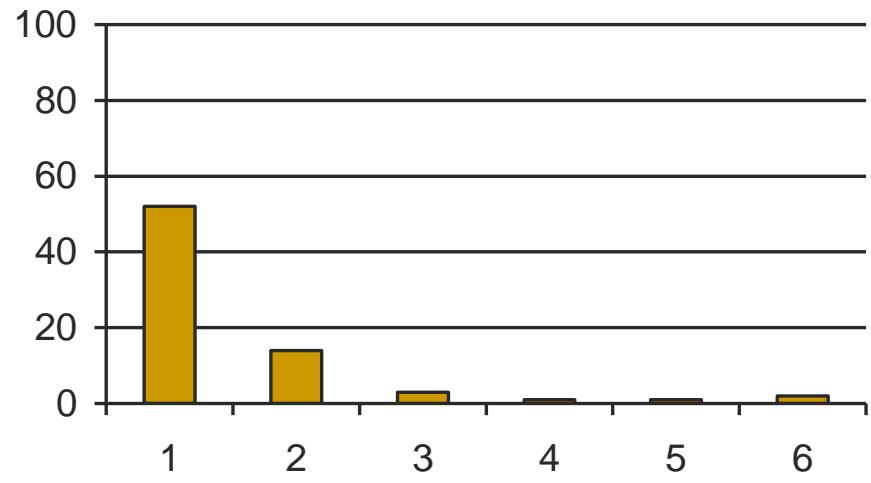

Fig. 2: the percentage of the frequency of attendances of epistaxis cases to the ENT department. 


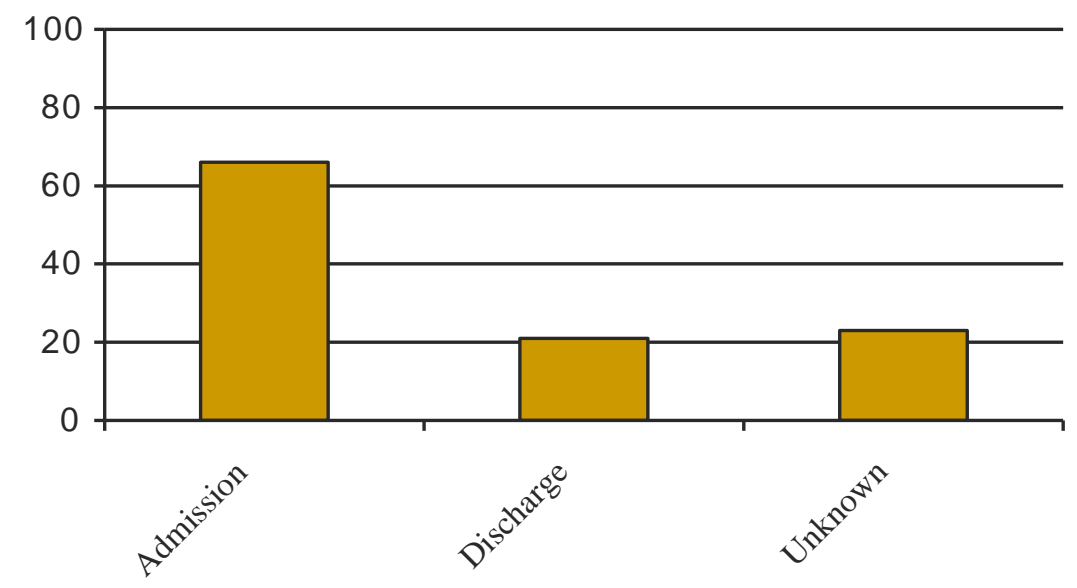

Fig. 3: the percentage of the distribution of hospital admissions among the attendances.

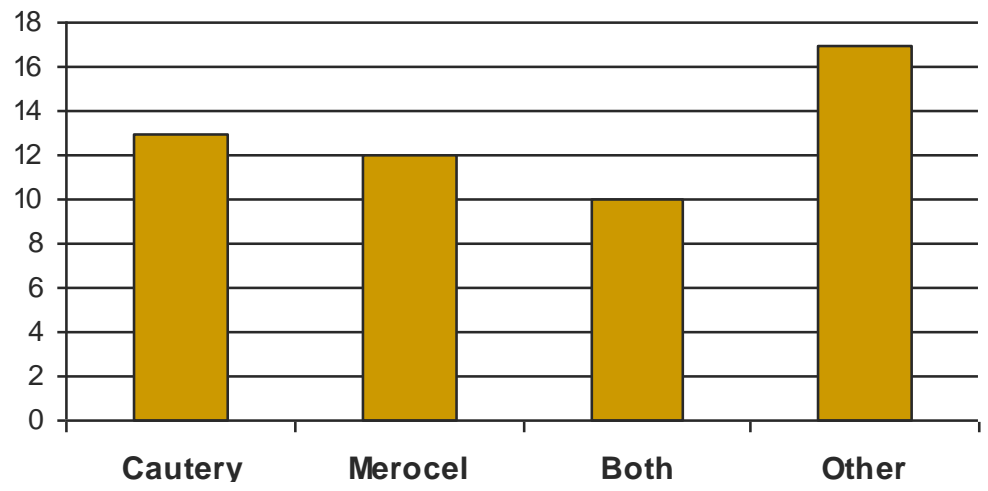

Fig. 4: the distribution of treatment lines among the patients.

\section{Discussion}

Epistaxis, or nasal bleeding, has been reported to occur in up to 60 percent of the general population. (Pollice and Yoder, 1997)

Among the 73 patients in this study, the incidence of epistaxis varied according to the age: higher incidences $(66 \%)$ of the patients were between 51 and 91 years old. This was partly compatible with Koh et al . (2000) study, as they reported that this condition has a bimodal distribution, with incidence peaks at ages younger than 10 years and older than 50 years. According to gender of the patients, there was no significant difference between male $(48 \%)$ and female $(52 \%)$ cases. This was also reported by Ahmed and Woolford, study (2003), as there was no sex predilection. But, some researchers reported that, epistaxis appears to occur more often in males than in females. (Rubin et al., 1999)

Regarding the etiology of epistaxis, it was divided, in most of studies, according to the origin of the bleeding into anterior and posterior epistaxis. But in our study this differentiation was not included.

As Derkay et al. (1989) reported, traumatic causes of epistaxis are predominantly anterior. Other cause of traumatic nasal injury rather than fractures, 


\section{Hesham A. Abdesallam et al}

especially in children, is insertion of objects into the nose.

As for the posterior epistaxis, it is usually a more serious problem than anterior epist-axis. The most common site of bleeding is posterior to the inferior turbinate. (De Weese, et al., 1999) Hypertension is frequently associated with posterior epistaxis. It may be more responsible for prolonging bleeding than for initiating it. (Jackson and Jackson., 1988). In our study, out of 73 patients, 13 had hypertension alone and 19 patients had hypertension with other chronic conditions. This means that $43.8 \%$ of the cases were hypertensive, this is less than reported by Jackson and Jackson, (1988), who reported that $64 \%$ of 75 patients with epistaxis had Hypertension . Furthermore, $48 \%$ of their 75 patients were severely hypertensive, with systolic pressures greater than $180 \mathrm{~mm}$ $\mathrm{Hg}$ or diastolic pressures greater than 110 $\mathrm{mm} \mathrm{Hg}$ at the time of the epistaxis.

In our study, five of our patients were on Warfarin, which can provoke severe epistaxis. This is the same as reported by McGill and Kulig. (1998). He added that aspirin even in low doses, is also a common cause of coagulopathy. In addition to other conditions such as: Liver disease, alcoholism, chemotherapy and hypovitaminosis which may decrease the production of platelets and clotting factors. Also, myeloma and leukemia may induce thrombocytopenia. None of These conditions were presented in our cases.

Although most patients with epistaxis can be treated as outpatients, hospital admission and close observation should be considered in some cases. In our study, among 110 attendances 66 were admitted for further assessment, while, the rest (44) were managed as outpatient cases. This is in agreement with Pond and Sizeland, (2000) who reported that hospital admission may be prudent only for patients with complicating comorbid conditions such as coronary artery disease, severe hypertension, or significant anemia. In contrast to Van Wyk et al. (2006) who presented a retrospective review of 116 patients with epistaxis. Only 17 required hospital admission. Forty-six patients were discharged and only seven (16
$\%)$ returned due to bleeding. The overall return rate was $11 \%$.

Lines of treatment of epistaxis vary. Initial management should include compression of the nostrils and plugging of the affected nostril with gauze or cotton that has been soaked in a topical decongestant for at least five minutes. The head should be tilted forward to prevent blood from pooling in the posterior pharynx, thereby avoiding nausea and airway obstruction. Then, every attempt should be made to locate the source of bleeding that does not respond to simple compression and nasal plugging. Diffuse oozing, multiple bleeding sites, or recurrent bleeding may indicate a systemic process such as hypertension, anticoagulation, or coagulopathy. In such cases, a hematologic evaluation should be performed. (Frazee and Hauser, 2000)

Then, local measures can be applied to control the nasal bleeding. One of these measures used in $31.5 \%$ of our cases was chemical cautery. The bleeding was controlled effectively in 13 patients by use of cautery alone and in 10 patients by combination of cautery and Merocel Packing. Interestingly, in Toner and Walby. (1990) study, they found no difference in efficacy between chemical cautery (silver nitrate stick) and electrocautery. However, electrocautery must be performed cautiously to avoid excessive destruction of healthy surrounding tissues as reported by Pond and Sizeland, (2000) which support our use of chemical cautery not the electrical one.

The results of our study were relatively better than Arikata et al. (2006) prospective study, which was conducted from March 2003 to February 2005, as 17 patients with epistaxis were included. 8 patients were successfully treated using the conventional packing method, 2 patients were treated using electrocauterization. 6 patients underwent endoscopic ligation of the sphenopalatine arteries while under general anesthesia. This is only used when posterior bleeding is suspected; therefore, selective ligation may be required. (Tan and Calhoun., 1999)

Regarding the efficacy of nasal Packing to control the epistaxis, it was 
successfully controlled in over $96.4 \%$ of patients treated with Merocel only, with no recurrence. This rate is similar to those reported in studies by Pringle et al. (1996) and Corbridge et al. (1995) who reported success rates of 91.5 and $92.6 \%$, respectively, in patients with epistaxis treated with Merocel pack. In our study, cases which were treated with one method, were relatively few, but are comparable to other comparative studies of nasal packing materials (Corbridge et al., 1995).

In our study, Rapid Rhino and Brighton balloon packing with Bismuth Iodoform Paraffin Paste used in 52.1\% of patients, with high success rate. Ioannis and Mark. (2006) performed a prospective study to compare the efficacy and patient tolerance of Merocel and Rapid Rhino nasal tampons in the treatment of epistaxis. A total of 42 patients were studied. Merocel was successful at controlling epistaxis in 17 $(81 \%)$ of the 21 patients initially treated with this pack. The results were similar using Rapid Rhino nasal packs. Sixteen patients $(76 \%)$ were treated effectively and bleeding was controlled. They found that there was no significant difference between the two types of pack inefficacy or patient discomfort with the pack in situ.

\section{Conclusion}

- There are far less cases of traumatic epistaxis than expected.

- Co-morbidity plays a pivotal role in the causation of epistaxis especially hypertension.

- A good percentage of epistaxis was controlled well with Cautery, Merocel or both

- Note keeping left a lot to be desired for.

\section{Recommendations}

- We suggest that lines of treatment of epistaxis should include initial manag-ement by

compression and plugging of the affected nostril with gauze or cotton that has been soaked in a topical decongestant for at least five minutes.

- Then local measures applied in the following sequence: chemical cautery followed by bilateral nasal packing with Merocel as the use of Merocel / Cautery can keep the cost to a minimum

- If in vain, Rapid Rhino with / without anterior packing with BIPP/Vaseline gauze.

- If nothing works $\rightarrow$ SPA ligation / diathermy.

- Juniors in A\&E should be taught the basic skills in the management of epistaxis. This would have a financial implications as well

- Clear note keeping.

\section{Refernces}

1. Ahmed A. and Woolford T J (2003): Endoscopic bipolar diathermy in the management of epistaxis: an effective and costefficient treatment. Clin. Otolaryngol., 28(3): 273-5

2. Arikata M, Seno S, Suzuki M, Sakurai H, Tojima I, and Shimizu T. (2006): Endoscopic ligation of maxillary and sphenopalatine artery for intractable epistaxis Nippon Jibiinkoka Gakkai Kaiho. 109(8):649-54.

3. Cassisi N J, Biller $\mathbf{H}$ F. and Ogura J H. (1971): Changes in arterial oxygen tension and pulmonary mechanics with the use of posterior packing in epistaxis: a preliminary report. Laryngoscope., 81(8): 1261-6

4. Choudhury N, Sharp H R, Mir N,and Salama N Y. (2004): Epistaxis and oral anticoa-gulant therapy. Rhinology., 42(2): 92-7 
5. Corbridge $\mathbf{R}$ J, Djazaeri $\mathbf{B}$, Hellier WPL and Hadley J. (1995). A prospective randomised controlled trial comparing the use of Merocel nasal tampons and BIPP in the control of acute epistaxis. Clin. Otolaryngol., 20:305-307

6. Derkay C S, Hirsch B E, Johnson $\mathbf{J}$ T. and Wagner $\mathbf{R} \mathbf{L}$. (1989). Posterior nasal packing. Are intravenous antibiotics really necessary? Arch Otolaryngol .,115: 439-41.

7. DeWeese D D, Saunders K, Schuller D, Schleuning A (1999): $2^{\text {nd }}$, edn. Otolaryngology-head and neck surgery. 7th ed. St. Louis: Mosby., 113-24.

8. Frazee $\mathbf{T}$ A. and Hauser M S. (2000). Nonsurgical management of epistaxis. J Oral Maxillofac Surg., 58:419-24.

9. Ioannis Moumoulidis, Mark R. Draper, Hemi Patel, Piyush Jani. and Timothy Price A (2006): Prospective randomised controlled trial comparing Merocel and Rapid Rhino nasal tampons in the treatment of epistaxis. Published online: 10, Springer-Verlag.

10. Jackson $\mathbf{K} \mathbf{R}$ and Jackson $\mathbf{R} \mathbf{T}$ (1988): Factors associated with active, refractory epistaxis. Arch Otolaryngol ., 114:862-5.

11. Jafek B W (1996): Anatomy and physiology of the nose. In: Jafek BW, Stark AK, eds. ENT Secrets. Philadelphia: Hanley \& Belfus., 77-83.

12. Koh E, Frazzini V I. and Kagetsu N J (2000): Epistaxis: vascular anatomy, origins, and endovascular treatment. AJR. Am. J. Roentgenol., 174: 845-51.

13. Marks, S C (2000): Nasal and Sinus Surgery. W. B. Saunders
Co. Philadelphia, PA.

14. McGill J. and Kulig K. (1998): Epistaxis. In: Rosen P, ed. Emergency medicine: concepts and clinical practice. $2 \mathrm{~d}$ ed. St. Louis: Mosby, 410-8.

15. Pollice $\mathbf{P}$ A. and Yoder M G. (1997): Epistaxis: a retrospective review of hospitalized patients. Otolaryngol Head Neck Surgery., 117: 49-53.

16. Pond F. and Sizeland A. (2000): Epistaxis. Strategies for management. Aust Fam Physician; 29:933-8.

17. Pringle $M$ B, Beasley $P$. and Brightwell A P. (1996): The use of Merocel nasal packs in the treatment of epistaxis. J. Laryngol Otol., 110:543-546

18. Rubin Grandis J, et al (1999): The management of epistaxis. $3 \mathrm{~d}$ ed. Alexandria, Va.: American Academy of Otolaryngology-Head and Neck Surgery Foundation.

19. Srinivasan V (2000): Surgical manage-ment of intractable epistaxis: audit of results. J. Laryngol. \& Otol., 114 (9): 697 700 .

20. Tan $\mathbf{L} \mathbf{K}$ and Calhoun $\mathbf{K} \mathbf{H}$ (1999): Epistaxis. Med Clin North Am; 83: 43-56.

21. Toner J G. and Walby $A P$. (1990): Comparison of electro and chemical cautery in the treatment of anterior epistaxis. J Laryngol Otol., 104: 617-8.

22. Van Wyk F C, Massey S, Worley G, and Brady S. (2006): Do all epistaxis patients with a nasal pack need admission? A retrospective study of 116 patients managed in accident and emergency according to a peer reviewed protocol. J. Laryngol. Otol., 11;:1-6 
Epistaxis Management 


\section{مناجزة الرعاف (النزيف الأنفى)}

\section{هشام عبد السلام- على خلف محروس - عبد السلام هاشم

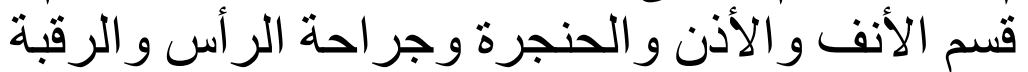 \\ كلية طب الأز هر}

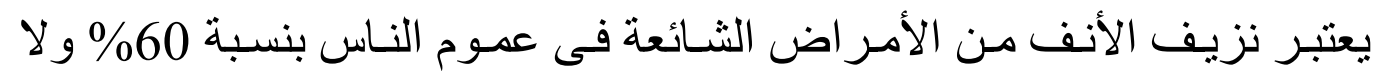

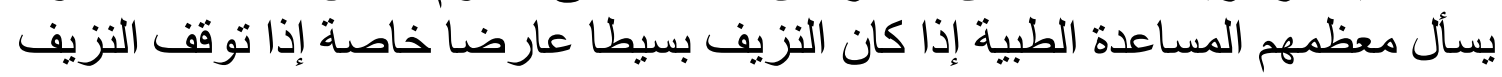

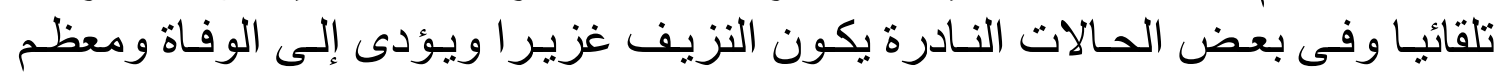

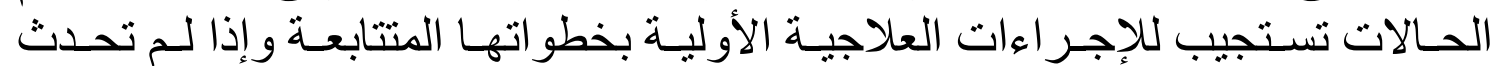
الإستجابة المرجوة فيجب تحديد مصدر النزيف و علاجها بوسائل أكثر تقدما.

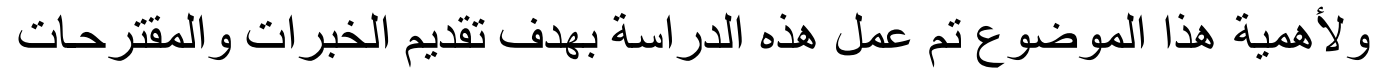

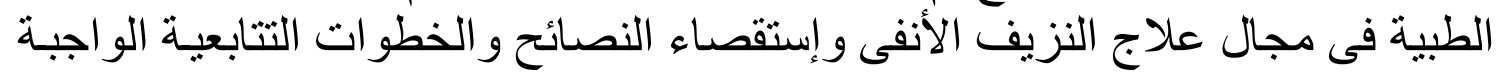

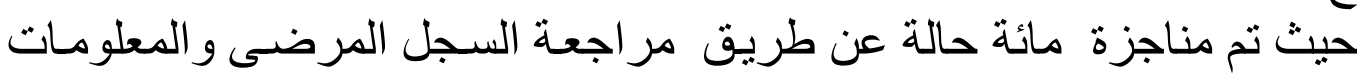

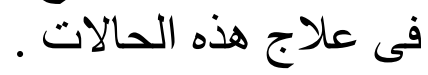

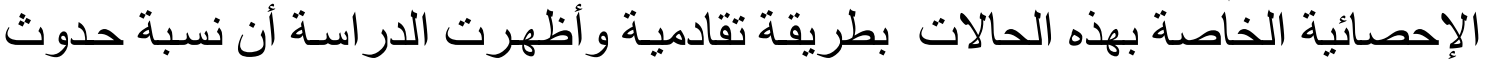

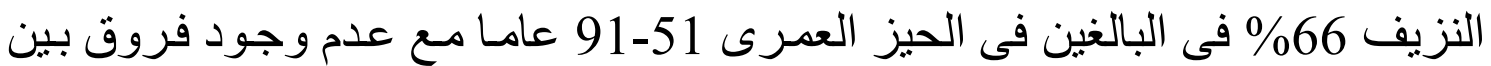

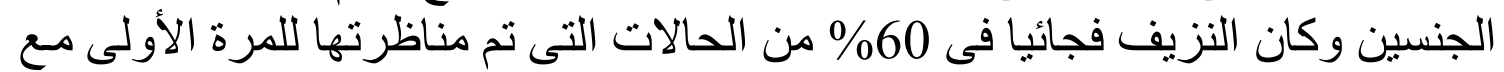

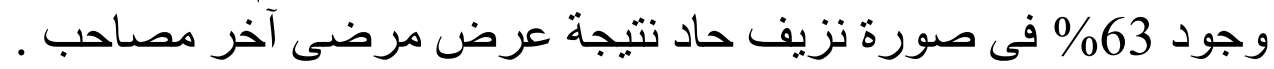

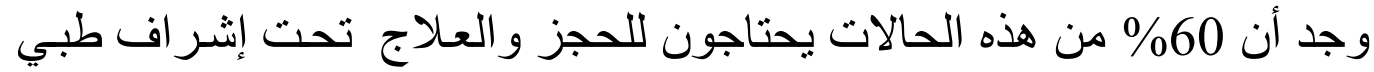

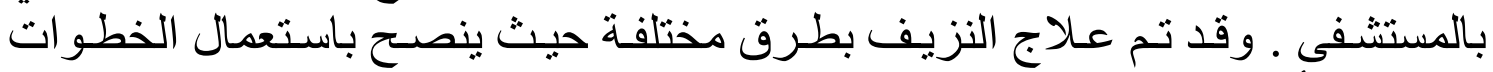

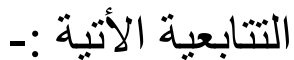

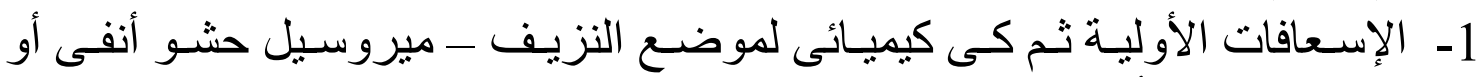

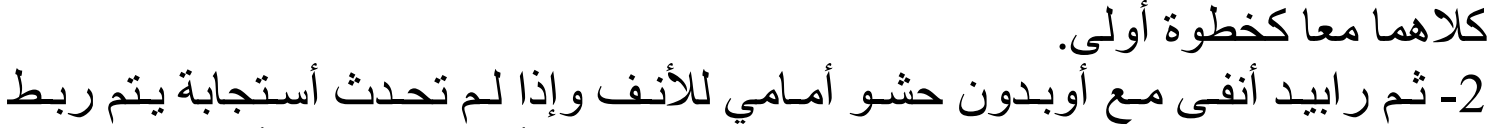

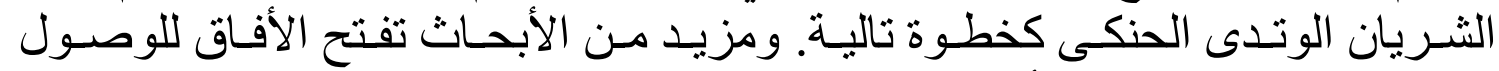

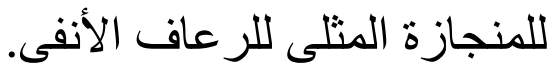

